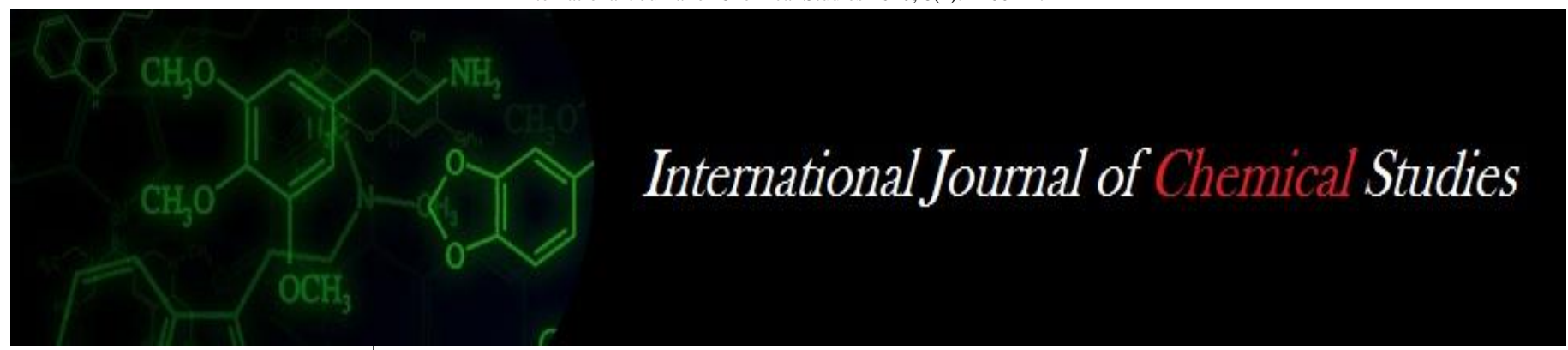

P-ISSN: 2349-8528

E-ISSN: 2321-4902

www.chemijournal.com

IJCS 2020; 8(4): 1466-1472

(C) 2020 IJCS

Received: 04-05-2020

Accepted: 06-06-2020

Wangdare Sachin Subash

Ph.D. Scholar, Food Safety and

Quality Assurance, Dairy

Chemistry Division, ICAR-

NDRI, Karnal, Haryana, India

K Jayaraj Rao

Principal Scientist, Dairy

Technology Division, ICAR-

NDRI (SRS), Bengaluru,

Karnataka, India

M Davuddin Baig

Ph.D. Scholar, Dairy Technology Division, ICAR- NDRI, Karnal,

Haryana, India

M Dharani Kumar

Ph.D. Scholar, Dairy Technology Division, ICAR- NDRI, Karnal, Haryana, India

\section{A Ankur}

M. Tech., Scholar, Dairy

Chemistry Division, ICAR-

NDRI, Karnal, Haryana, India

\section{KS Kanna}

Ph.D. Scholar, Department of management studies, Karunya University, Coimbatore, Tamil Nadu, India

Corresponding Author: Wangdare Sachin Subash Ph.D. Scholar, Food Safety and Quality Assurance, Dairy Chemistry Division, ICARNDRI, Karnal, Haryana, India

\section{Correlations among sensory, textural and chemical parameters of paneer (Indian soft cheese)}

\author{
Wangdare Sachin Subash, K Jayaraj Rao, M Davuddin Baig, M Dharani \\ Kumar, A Ankur and KS Kanna
}

DOI: https://doi.org/10.22271/chemi.2020.v8.i4n.9818

\begin{abstract}
Paneer is is prepared by the heat and acid coagulation process of cow or buffalo milk. However, the quality of paneer mainly depends upon the quality of milk, heat treatment, moisture content in paneer, and storage condition. Therefore, in the present study, correlations were studied among sensory, physicchemical, textural, and microbiological parameters of paneer samples. There have been noted some good correlations like: body and texture (BT) score versus fat content $(\mathrm{r}=0.879)$, flavor score versus body and texture score $(r=0.931)$, overall acceptance score versus body and texture score $(r=0.974)$, overall acceptance score versus flavor score $(r=0.947)$ and chewiness verses gumminess $(r=0.932)$.
\end{abstract}

Keywords: Sensory properties, Chemical and textural properties, Correlations

\section{Introduction}

Paneer is an important traditional indigenous milk product, which is prepared by the heat and acid coagulation process of milk (Chitranayak et al. 2017) ${ }^{[15]}$. Food safety \& Standard Authority of India 2006 defined paneer as a product obtained from cow or buffalo milk or a combination thereof by precipitation with sour milk, lactic acid, or citric acid (Wangdare, Rao, Mishra \& Datir, 2017) ${ }^{[36]}$. Moisture content shall not be more than 70.0 percent, and milk fat content shall not be less than 50.0 percent of the dry matter (Wangdare et al 2017) ${ }^{[36]}$. Paneer has great importance in a daily meal for the preparation of a variety of culinary dishes and snacks due to rich in quality proteins, fat, minerals as well as vitamins, which helps in fulfillment of basic nutritional demands of consumer (Desale, Dhole, Deshmukh \& Nimase, 2009; Goyal, Singh \& Goyal, 2007; Khan \& Pal, 2011) ${ }^{[17,23,27]}$. Chemical composition of paneer consists of 40 percent total solids, which include 25 percent fat, 17.5 percent proteins, 2 percent carbohydrates, and 1.5 percent minerals, which is one of the major sources of vegetarian consumers (Sachdeva, 1998). The main quality attributes of paneer that should be a uniform with the pleasing white appearance and a greenish tinge when prepared from buffalo milk and light yellow when prepared from cow milk. Moreover, quality attributes include mildly acidic flavor with a slightly sweet taste and a soft, cohesive, and compact texture (Kumar, Rai, Niranjan \& Bhat, 2014) ${ }^{[28]}$. It has stated that nearly about 4-5\% of the total milk produced, which converted into paneer in India (Chandan, 2007) ${ }^{[14]}$. Paneer has a short storage life of about 5-7 days at refrigeration storage with limited deterioration in the quality. However, the freshness of the paneer lost after 3 days (Dhankhar, 2014) ${ }^{[18]}$. Furthermore, another study observed that the quality of paneer was not uniform, which mainly depends upon the quality of milk, heat treatment, the moisture content in paneer, and storage condition (Agarwal \& Das, 2001; Masud, Shehla \& Khurram, 2007; Das \& Ghatak, 1999) ${ }^{[2,29,16]}$. Many researchers studied relationships between subjective and objective responses, for example between textural properties and sensory acceptance (Meullenet, Lyon, Carpenter \& Lyon, 1998; Skriver, Holstborg \& Qvist, 1999; Drake, Gerard, Truong \& Daubert, 1999) [30, 32, 20], chemical characteristics and sensory properties (Casiraghi, Lucisano \& Pompei, 1989; Janhøj, Petersen, Frøst \& Ipsen, 2006) ${ }^{[25]}$ and total solids and viscosity (Fernandez-Martin, 1972) ${ }^{[22]}$. Establishing a mathematical relationship provides us explanations about product 
characteristics. However, very few studies carried on the relation between physicochemical, sensory, textural, and microbiological quality of paneer. In the present study, a total of 8 brands have been analyzed, including self-prepared and each brand with 10 packets for their physicochemical, textural, sensory, and microbial quality. Correlations were studied among sensory, physic-chemical, textural, and microbiological parameters of paneer samples.

\section{Materials and methods \\ Collection of paneer samples}

The objective was to collect paneer samples from the Bengaluru market. Initially, the shops where paneer was being sold in Bengaluru city were surveyed for their locations. Based on the information, the shops were selected randomly for a collection of paneer samples. A total of 80 samples of paneer from different shops were collected and brought to the laboratory in an icebox container. Care was taken to collect packets within the use-before-date.

\section{Chemical analysis}

Moisture content in paneer was determined, according to BIS (1983) ${ }^{[10]}$. The fat content of paneer was determined by the method described for cheese, according to BIS (1977) ${ }^{[9]}$. Total nitrogen or total protein in paneer was determined as per the method described in AOAC (2005) [5] with modification. Lactose/sugar was derived by a difference in the total of the major constituents like moisture, protein, fat, and ash from 100, as described by AOAC (1990) ${ }^{[4]}$. The ash content of paneer was estimated by the method of AOAC (2005) ${ }^{[5]}$. The $\mathrm{pH}$ of paneer was measured as described by Awad, Hassan \& Halaweish. (2005) ${ }^{[6]}$. Titratable acidity in paneer was determined by titration method BIS (1983) ${ }^{[10]}$.

\section{Evaluation of paneer for sensory attributes}

Sensory attributes play a major role in determining the acceptability of a food product as well as the ultimate purchase decision of consumers (Baig et al. 2019) ${ }^{[7]}$. The evaluation was carried out room temperature under proper lighting. Each block of refrigerated paneer samples was cut into rectangular cubes of approximately $2 \mathrm{~cm} \times 2 \mathrm{~cm}$, tempered to room temperature and served to panel of semi-trained judges (minimum of six members, of which four were males and two females; two from age group 25 to 30 years, two from 30 to 40 years and two from above 50 years) for evaluation of sensory attributes like color and appearance, body and texture, flavor and overall acceptability on a 9-point hedonic scale (Peryam and Pilgrim 1957; Borrin et al. 2018; Vital et al. 2018) ${ }^{[31,11,33]}$. The sensory panel was drawn from faculty and post-graduate students of the Institute. The panel members were chosen based on their aptitude, willingness to spare time, and availability for sensory evaluation. Further, all the chosen panel members were regular consumers of paneer and are well acquainted with the quality and defects of paneer. Hence, variation in the sensory evaluation among the panelists was minimal.

\section{Colour characteristics}

The Colour of the paneer samples was measured by ScannerAdobe Photoshop (SAP) method (Vyawahare and Rao, 2012) [34].

\section{Instrumental textural characteristics}

Texture profile analysis (TPA) parameters, viz. hardness, cohesiveness, springiness, and chewiness were determined using the Stable Microsystems (Godalming, UK) TA-XT plus Stable Micro System Texture Analyzer (UK) by two-bite linear compression (Dwarakanath et al. 2013) ${ }^{[21]}$. A circular disc probe $75 \mathrm{~mm}(\mathrm{P} / 75)$ diameter was attached to the crosshead of the machine. The instrument test settings of TA.XT plus instrument were as follows: option: return to start; test mode: compression; pre-test speed: $1 \mathrm{~mm} / \mathrm{sec}$; test speed: 5 $\mathrm{mm} / \mathrm{sec}$; post-test speed: $5 \mathrm{~mm} / \mathrm{sec}$; target mode: distance; distance: $10 \mathrm{~mm}$; time: $5 \mathrm{sec}$; trigger type: auto (Force); trigger force: $2 \mathrm{~g}$; break mode: off; advanced option: on; probe: $\mathrm{P} / 75$ plunger probe. The probe was calibrated to a distance of $50 \mathrm{~mm}$, from the base of the platform. The paneer samples were cut into $20 \times 20 \times 20 \mathrm{~mm}$ cubes and were tempered to $25{ }^{\circ} \mathrm{C}$ in a temperature-controlled cabinet for $1-2 \mathrm{~h}$ and the tests were carried out at the same temperature. The probe was positioned centrally over the sample surface and allowed to compress the product. The probe traveled to a distance of $10 \mathrm{~mm}$, compressing the product by $50 \%$ of its height and returned to the original position (1st bite); after a time gap of $5 \mathrm{sec}$, the probe again compressed the sample and returned to the original position (2nd bite), generating a force-time curve. The texture profile parameters were determined from the force-time curve as given by Dwarakanath et al. (2013) ${ }^{[21]}$

\section{Correlation analysis}

Pearson's correlation coefficient (r), which is a measure of the strength of the association among physic-chemical, textural, microbiological, and sensory scores, was first computed (Akoglu, 2018) using SPSS software. Physico-chemical parameters included: $\mathrm{pH}$, acidity, moisture, fat, protein, ash, lactose, L, a, b (color parameters); textural parameters included: adhesiveness, cohesiveness, hardness, springiness, gumminess, chewiness, resilience; microbiological parameters: Total bacterial count (TBC) and yeast and mold count (YMC); sensory parameters: color and appearance, flavor, body and texture and overall acceptance scores. From among the above relationships, only those who showed an $r$ value of above 0.70 were considered for further regression analysis. The goodness of fit was evaluated by R2 as well as Root mean square (RMS) value. The R-squared value means that its product with 100 indicates the percent variation that can be explained by the variable under consideration. The intercept in a multiple regression model is the mean for the response when all of the explanatory variables take on the value 0 . The regression coefficient of a variable is interpreted as the change in the response based on a 1-unit change in the corresponding explanatory variable keeping all other variables held constant. The models exhibiting R2 values more than 0.70 were considered as best fit models. The goodness of fit was further evaluated by computing RMS values and residual plots between the experimental and predicted values. The lower the RMS value, the better was the goodness of fit. RMS value of less than 10.0 was considered as a good fit (Akoglu, 2018). Linear regressions were carried out between sensory score and chemical parameters using the SPSS package. Relationships between subjective and objective responses were studied by many researchers, for example between textural properties and sensory acceptance (Meullenet et al. 1998; Skriver et al. 1999; Drake et al. 1999) $[30,32,20]$ chemical characteristics and sensory properties (Casiraghi et al. 1989; Janhoj et al. 2006) ${ }^{[13,25]}$, and total solids and viscosity (Fernandez-Martin, 1972) [22]. Establishing a mathematical relationship provides us explanations about product characteristics and helps in the 
holistic evaluation of products' quality. Few research papers are available describing the comparison of sensory and textural analysis of semisolid food products.

\section{Statistical analysis}

The data collected were arranged in a completely randomized design and analyzed by one ANOVA technique using SPSS software. Post Hoc tests of Tukey were carried out to determine the significant difference between any two brands of paneer. Regressions were carried out between sensory score and chemical parameters using the SPSS package.

\section{Results and discussion \\ Pearson correlations among sensory, textural and chemical characteristics of paneer}

The data of sensory scores, chemical parameters, instrumentally measured textural parameters, and microbial parameters were correlated with each other. Pearson's r values indicated that many correlations were not satisfactory ( $\mathrm{r}<0.70)$. Only correlations with $\mathrm{r} 2$ with more than 0.70 are given in Table 1. In this correlation study, it was observed that some correlations were found satisfactory, and some were excellent. Very good correlations included body and texture score versus fat content $(\mathrm{r}=0.879)$, flavor score versus body and texture score $(\mathrm{r}=0.931)$, overall acceptance score versus body and texture score $(\mathrm{r}=0.974)$, overall acceptance score versus flavor score $(\mathrm{r}=0.947)$ and chewiness verses gumminess $(r=0.932)$ (Table 1$)$ and rest of sensory, textural and chemical parameters showed satisfactory correlations (Table 1). These observations show the possibility of regressions between the data, which showed satisfactory Pearson's correlations. Hence, the various data were subjected to univariate and multiple linear regression analyses.

Table 1: Pearson correlations* among sensory, textural and chemical characteristics of paneer collected from Bengaluru market

\begin{tabular}{|c|c|c|}
\hline S. No. & Correlation between & r \\
\hline 1 & Color and appearance score - Moisture \% & 0.720 \\
\hline 2 & Body and texture score - Moisture \% & 0.794 \\
\hline 3 & Body and texture score - Fat \% & 0.879 \\
\hline 4 & Flavour score - Fat \% & 0.812 \\
\hline 5 & Overall acceptance score - Moisture \% & 0.770 \\
\hline 6 & Overall acceptance score - Fat \% & 0.774 \\
\hline 7 & Flavour score - Color and appearance score & 0.729 \\
\hline 8 & Flavour score - Body and texture score & 0.931 \\
\hline 9 & Overall acceptance score - Color and appearance score & 0.774 \\
\hline 10 & Overall acceptance score - Body and texture score & 0.974 \\
\hline 11 & Overall acceptance score - Flavour score & 0.947 \\
\hline 12 & Color and appearance score- Body and texture score & 0.764 \\
\hline 13 & Fat content - Moisture \% & 0.894 \\
\hline 14 & Gumminess - Hardness & 0.875 \\
\hline 15 & Chewiness - Hardness & 0.800 \\
\hline 16 & Chewiness - Gumminess & 0.932 \\
\hline
\end{tabular}

Note: All the correlations are significant at $p<0.05 ; * \mathrm{r}$ values more than 0.70 are given

\section{Regression between sensory score and chemical parameters}

When color and appearance (CA) score was regressed with moisture \%, the regression was found to be reduced $(\mathrm{R} 2=$ 0.46), indicating that the CA score was not dependent on the moisture content of paneer. However, when fat $\%$ also was included in the regression, the $\mathrm{R} 2$ value increased to 0.50 , showing some contribution of fat content to the CA score. Thus it was observed that as protein, lactose, ash, and acidity were included in regression analysis, the $\mathrm{R} 2$ gradually increased, indicating that all these parameters did contribute to the CA score. Yet, the regression was not satisfactory based on the final R2 value of 0.57 (well below 0.70) (Table 2). These observations indicate that the CA of paneer is not much influenced by chemical composition.

Body and texture (BT) scores have an R2 value of 0.61 , which was not satisfactory. However, BT has a satisfactory relation with fat content (R2 0.75). However, when more chemical parameters are added to regression, the $\mathrm{R} 2$ value remained the same or decreased to 0.73 . This indicates that the BT score is the primary function of fat content and not any other chemical parameter studied. R2 between flavor score and fat content was 0.61 , which was not satisfactory though statistically significant. When all the chemical parameters are included in the regression, the $\mathrm{R} 2$ value rose to 0.71 , which indicates that the flavor score is influenced not only by fat content but also on moisture, protein, mineral, and acidity (Table 2). The R2 between Overall acceptability (OA) score and moisture was 0.75 , which indicates a satisfactory relationship. However, R2 remained the same, even when other chemical parameters were added to regression (Table 2). This indicates that the overall acceptance of paneer is mainly dependent on the moisture content. Khamrui, Dutta \& Dave (2004) ${ }^{[26]}$ reported that sensory textural parameters exhibited significant correlations with instrumental measurements; the former was more efficient in registering changes in brittleness and stickiness attributes. It was also a known fact that lowfat paneer has the limitations of textural attributes.

Table 2: Regressions between sensory score and chemical parameters

\begin{tabular}{|c|l|c|}
\hline S. No. & \multicolumn{1}{|c|}{ Regression between } & $\mathbf{R}^{\mathbf{2}}$ value \\
\hline 1 & Color and appearance score - Moisture \% & 0.46 \\
\hline 2 & Color and appearance score - Moisture\%+Fat\% & 0.50 \\
\hline 3 & Color and appearance score - Moisture\%+Fat\%+ Protein\% $\%$ & 0.51 \\
\hline 4 & Color and appearance score - Moisture \%+Fat\%+ Protein\%+Lactose\% & 0.54 \\
\hline 5 & Color and appearance score - Moisture\%+Fat\%+ Protein\%+ Lactose\%+ Minerals\% & 053 \\
\hline
\end{tabular}




\begin{tabular}{|c|c|c|}
\hline 6 & Color and appearance score - Moisture $\%+$ Fat $\%+$ Protein $\%+$ Lactose $\%+$ Minerals $\%+$ Acidity $\%$ & 0.57 \\
\hline 7 & Body and texture score - Moisture \% & 0.61 \\
\hline 8 & Body and texture score - Fat $\%$ & 0.75 \\
\hline 9 & Body and texture score - Moisture $\%+$ Fat $\%$ & 0.74 \\
\hline 10 & Body and texture score - Moisture $\%+$ Fat $\%+$ Protein $\%$ & 0.74 \\
\hline 11 & Body and texture score - Moisture $\%+$ Fat $\%+$ Protein $\%+$ Lactose $\%$ & 0.73 \\
\hline 12 & Body and texture score - Moisture $\%+$ Fat $\%+$ Protein $\%+$ Lactose $\%+$ Minerals $\%$ & 0.73 \\
\hline 13 & Body and texture score - Moisture $\%+$ Fat $\%+$ Protein $\%+$ Lactose $\%+$ Minerals $\%+$ Acidity $\%$ & 0.73 \\
\hline 14 & Flavour score - Fat $\%$ & 0.65 \\
\hline 15 & Flavour score - Moisture $\%+$ Fat $\%$ & 0.64 \\
\hline 16 & Flavour score - Moisture $\%+$ Fat $\%+$ Protein $\%$ & 0.67 \\
\hline 17 & Flavour score - Moisture $\%+$ Fat $\%+$ Protein $\%+$ Lactose $\%$ & 0.69 \\
\hline 18 & Flavour score - Moisture $\%+$ Fat $\%+$ Protein $\%+$ Lactose $\%+$ Minerals $\%$ & 0.68 \\
\hline 19 & Flavour score - Moisture $\%+$ Fat $\%+$ Protein $\%+$ Lactose $\%+$ Minerals $\%+$ Acidity $\%$ & 0.71 \\
\hline 20 & Overall acceptance score- Moisture\% & 0.75 \\
\hline 21 & Overall acceptance score- Moisture $\%+$ Fat $\%$ & 0.75 \\
\hline 22 & Overall acceptance score - Moisture \%+Fat \%+Protein $\%$ & 0.75 \\
\hline 23 & Overall acceptance score - Moisture $\%+$ Fat $\%+$ Protein $\%+$ Lactose $\%$ & 0.75 \\
\hline 24 & Overall acceptance score - Moisture $\%+$ Fat $\%+$ Protein $\%+$ Lactose $\%+$ Minerals $\%$ & 0.75 \\
\hline 25 & Overall acceptance score - Moisture $\%+$ Fat $\%+$ Protein $\%+$ Lactose $\%+$ Minerals $\%+$ Acidity $\%$ & 0.75 \\
\hline
\end{tabular}

\section{Regression between chemical parameters}

The chemical constituents of paneer include moisture, fat, protein, ash, and lactose contents. Their contents may be interdependent on each other. For example, fat content is dependent on Moisture content $(\mathrm{R} 2=0.68)$; however, the higher $\mathrm{R} 2$ value of 0.88 indicates that the fat content is dependent on moisture, protein, and lactose put together (Table 3).

Table 3: Regressions between chemical parameters

\begin{tabular}{|c|c|c|}
\hline S. No. & Regression between & $\mathbf{R}^{\mathbf{2}}$ \\
\hline 1 & Fat - Moisture\% & 0.68 \\
\hline 2 & Fat - Moisture\% + Protein \% & 0.71 \\
\hline 3 & Fat - Moisture $\%$ + Protein $\%$ + Lactose $\%$ & 0.88 \\
\hline
\end{tabular}

Note: All the regressions are significant at $\mathrm{p}<0.05 ;{ }^{*} \mathrm{R}^{2}$ values more than 0.70 are given

\section{Regression between sensory parameters}

Table 4: Regressions between sensory parameters

\begin{tabular}{|c|c|c|}
\hline $\begin{array}{c}\text { S. } \\
\text { No. }\end{array}$ & Regression between & $\mathbf{R}^{2}$ \\
\hline 1 & Flavour score - Color and appearance score & 0.65 \\
\hline 2 & Flavour score - Body and texture score & 0.85 \\
\hline 3 & Overall acceptance score - Color and appearance score & 0.66 \\
\hline 4 & Overall acceptance score - Body and texture score & 0.93 \\
\hline 5 & $\begin{array}{c}\text { Overall acceptance score- Color and appearance score } \\
+ \text { +Flavour score }\end{array}$ & 0.66 \\
\hline 6 & $\begin{array}{c}\text { Overall acceptance score- Color and appearance score } \\
\text { +Body and texture score }\end{array}$ & 0.94 \\
\hline 7 & $\begin{array}{c}\text { Overall acceptance score- Flavour score +Body and texture } \\
\text { score }\end{array}$ & 0.94 \\
\hline 8 & $\begin{array}{c}\text { Overall acceptance score- Color and appearance score } \\
+ \text { Flavour score+ Body and texture score }\end{array}$ & 0.95 \\
\hline
\end{tabular}

Note: All the regressions are significant at $p<0.05 ; * \mathrm{R}^{2}$ values more than 0.70 are given

Flavour score and CA have R2 of 0.65 , which indicates flavor is influenced to a certain extent by color and appearance. That means the right color and appearance might influence the consumer for better acceptance of flavor. However, the flavor score is significantly influenced by (body and texture) BT score. This means if BT is good, most probably flavor also be evaluated as useful. Psychologically, the consumer may be influenced by good appearance and BT. The overall acceptance score is mainly influenced by BT, as observed from $\mathrm{R} 2$ of 0.93 . If $\mathrm{CA}$ and flavor are included in the regression, the R2 only rose to 0.94 (Table 4). This underlines the importance of BT in determining the sensory acceptance of paneer samples. Probably this observation suggests that in the 100 point scorecard of paneer, maximum marks should be allotted to BT rather than flavor. Thus, OA is not determined by $\mathrm{CA}$ and flavor score alone, but highly dependent on BT score in combination with $\mathrm{CA}$ and flavor. OA is decided by $\mathrm{CA}$, flavor, and BT of paneer (Table 4).

\section{Regression between TPA parameters}

Regression analyses also showed some good relationships among TPA parameters. For example, gumminess Vs Hardness + Cohesiveness $(\mathrm{R} 2=0.96)$ and chewiness Vs Springiness + gumminess $(\mathrm{R} 2=0.92)$ showed $\mathrm{R} 2$ values higher than 0.90 . The rest of the TPA parameter showed satisfactory regression (Table 5). TPA parameters are interdependent. This is obvious because some of them are mathematically derived from other TPA parameters. For instance, Gumminess = Hardness $\mathrm{x}$ Cohesiveness; Chewiness $=$ Hardness x Springiness x Cohesiveness (Bourne, 2002) ${ }^{[12]}$.

Table 5: Regressions between TPA parameters

\begin{tabular}{|c|c|c|}
\hline S. No. & Regression between & $\mathbf{R}^{\mathbf{2}}$ \\
\hline 1 & Gumminess - Hardness & 0.77 \\
\hline 2 & Gumminess - Hardness + Cohesiveness & 0.96 \\
\hline 3 & Chewiness - Hardness & 0.65 \\
\hline 4 & Chewiness - Hardness + Cohesiveness & 0.80 \\
\hline 5 & Chewiness - Hardness + Cohesiveness + Springiness & 0.86 \\
\hline 6 & Chewiness - Gumminess & 0.87 \\
\hline 7 & Chewiness - Springiness + Gumminess & 0.92 \\
\hline
\end{tabular}

Note: All the regressions are significant at $p<0.05 ; * \mathrm{R}^{2}$ values more than 0.70 are given

\section{Best fit relations}

From among the relationships studied, the best ones are discussed. Chemical parameters influence the sensory score; however, no sensory score was influenced by one chemical parameter alone except fat content, which alone influenced 
the BT score (R2 0.75). A combination of chemical parameters influenced the sensory scores. For example, the flavor is a function of all the compositional parameters that indicate that the flavor of paneer is a complex phenomenon determined by several parameters (Table 6). However, among the chemical parameters, fat content and acidity have the most influence, as indicated by higher regression coefficients (0.1043 and 0.7516) (Table 6). Flavour score was influenced by BT (R2 0.85), which means if BT is right, then most probably flavor is also perceived to be good. Whereas OA is dependent on all the sensory attributes CA, BT, and Flavour. It was further observed that fat content is dependent on moisture, protein, and lactose contents (Table 6). Di Monaco, Cavella \& Masi (1995) reported that sensory attribute aroma and flavor descriptors correlated with organic acid concentrations and sensory parameter best correlated with the TPA parameter. Khamrui et al. (2004) [26] reported that sensory textural parameters exhibited significant correlations with instrumental measurements. Yamul, Galmarini, Lupano \& Zamora (2013) ${ }^{[35]}$ reported that good correlation was obtained between the instrumental and sensory attributes hardness, cohesiveness, and elasticity. But, surprisingly, in the present study, no good correlation was obtained between sensory scores and instrumentally determined textural attributes. There was no relationship between sensory score and instrumentally measured color parameters as well as microbial counts also. These observations indicate that wide variations exist in instrumentally measured textural attributes, instrumentally measured color attributes, and microbial counts, whereas variations were least in sensory scores. This is the possible reason for no functional correlations were existing among the sensory and textural parameters. Moreover, judges were not insistent upon any specific quality on which sensory score can be varied. This is more so because in this study 9-point Hedonic scale was used rather than a 100 point scorecard. The hedonic scale is indicative of only a 'liking level' than any critical evaluation. This could be the reason for many weak correlations among the data of the present study.

\section{Residual plots}

Residual plots between predicted values using best fit models (Table 6) and experimental values were generated and the trend observed. The goodness of fit was also shown by RMS values. The residual plots of BT scores predicted from fat content, flavor score predicted from moisture + fat + protein + lactose +ash + Acidity values, flavor score predicted from fat $\%$, and OA score predicted from CA +Flavour +BT scores are portrayed in Fig. 1, 2, 3, and 4, respectively. It may be seen from the plots that the R2 values lay more than 0.75 , and RMS values were between 1.29-5.73. This indicates that the above relationships do follow a mathematical pattern and can be predicted from each other satisfactorily. For example, we can predict BT acceptance based on fat content. We can predict flavor acceptance from chemical composition and acidity. We can predict flavor acceptance from BT, which means if BT is good, most probably flavor is also good. Not only can a judge score OA himself, but also it is possible to predict the OA score from CA, flavor, and BT scores.

Table 6: Best fit relations

\begin{tabular}{|c|c|c|c|c|c|c|c|c|c|c|}
\hline $\begin{array}{l}\text { S. } \\
\text { No. }\end{array}$ & Regression between & b0 & b1 & b2 & b3 & b4 & b5 & b6 & $\begin{array}{c}\text { Adj } \\
\mathbf{R}^{2}\end{array}$ & RMS \\
\hline 1 & Body and texture score - Fat $\%$ & 4.976 & 0.1082 & - & - & - & - & - & 0.75 & 3.18 \\
\hline 2 & $\begin{array}{c}\text { Flavour score }- \text { Moisture } \%+\text { Fat } \%+\text { Protein } \%+\text { Lactose } \%+\text { Minerals } \%+ \\
\text { Acidity } \%\end{array}$ & 6.033 & -0.010 & 0.1043 & 0.00467 & - & - & $\begin{array}{c}- \\
0.7516 \\
\end{array}$ & 0.71 & 4.23 \\
\hline 3 & $\begin{array}{l}\text { Flavour score }- \text { Body and texture score } \\
\end{array}$ & -1.782 & 1.2168 & - & - & - & - & - & 0.85 & 3.43 \\
\hline 4 & $\begin{array}{l}\text { Overall acceptance score }- \text { Color and appearance }+ \text { Flavour +Body and } \\
\text { texture score }\end{array}$ & 0.466 & 0.1363 & 0.1679 & 0.6292 & - & - & - & 0.95 & 1.29 \\
\hline 5 & Fat - Moisture $\%+$ Protein $\%+$ Lactose $\%$ & 83.753 & $\begin{array}{c}- \\
0 / 8727\end{array}$ & -0.60 & -0.8365 & - & - & - & 0.88 & 5.73 \\
\hline
\end{tabular}

Note: b0, b1, b2, b3, b4, b5, b6 - regression coefficients; All the regressions are significant at $p<0.05$;

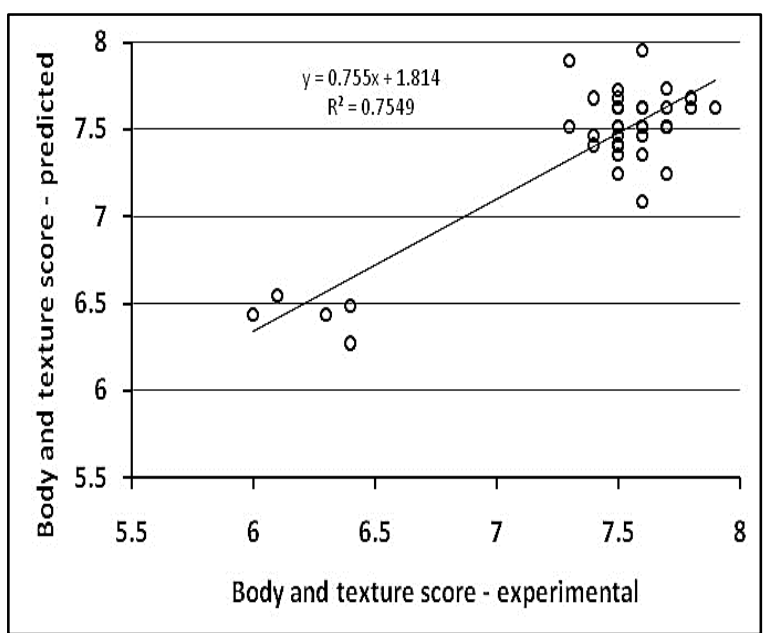

Note: predicted values computed from model: $\mathrm{BT}$ score $=4.976+$ 0.1082 . Fat\% $\left(R^{2}=0.75\right)$

Fig. 1: Residual plot of experimental body and texture scores and predicted body and texture scores

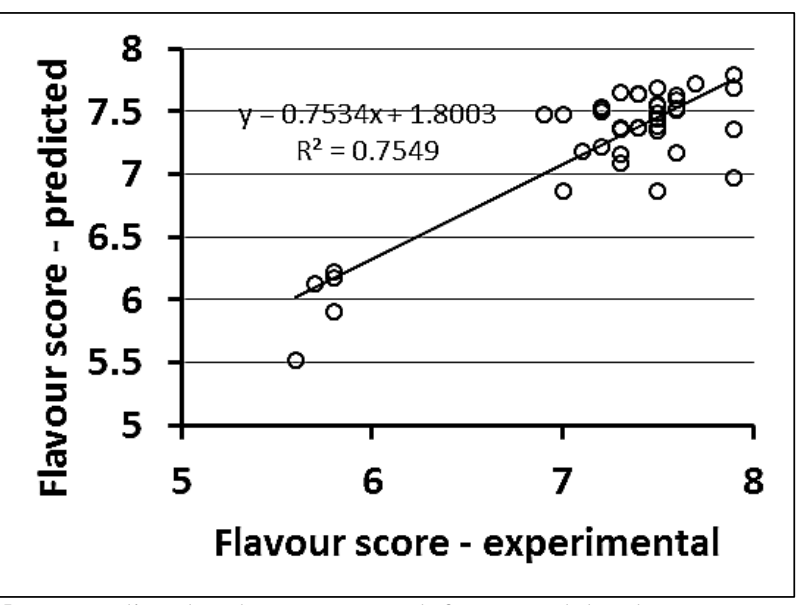

Note: predicted values computed from model: Flavour score $=$ 6.033 - 0.010.Moisture $\%+0.1043$. Fat $\%+0.00467$. Protein $\%-$ 0.0723. Lactose\% - 0.01253. Ash\% - 0.7516. Acidity\% ( $\left.\mathrm{R}^{2} 0.71\right)$

Fig. 2: Residual plot of experimental flavor scores and predicted flavor scores 


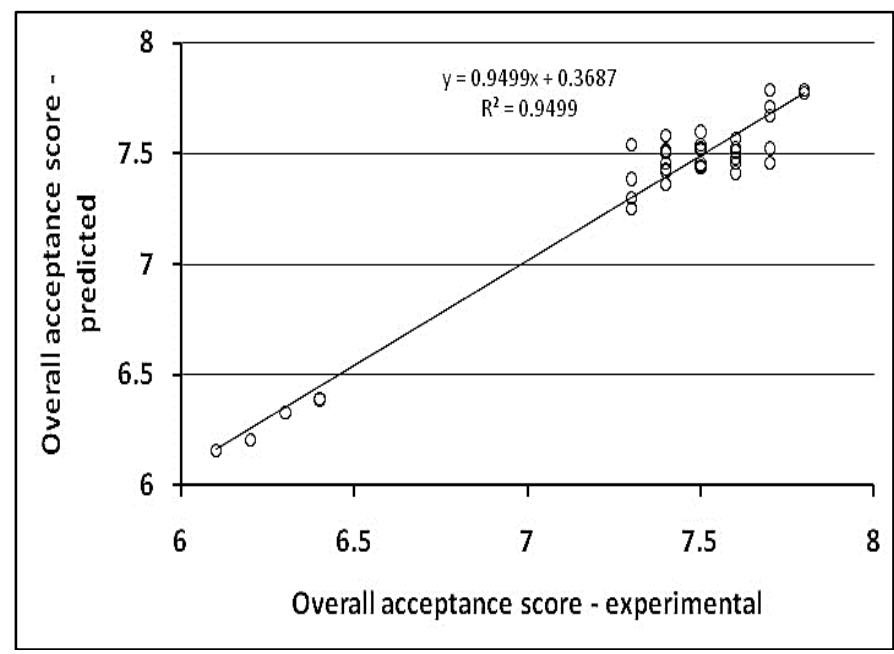

Note: Predicted values computed from model: OA score $=0.466+$ 0.1363.CA score +0.1679 . Flavour score +0.6292 . BT score $\left(\mathrm{R}^{2}\right.$ $0.95)$

Fig 4: Residual plot for experimental overall acceptance score and predicted overall acceptance score

\subsection{Characteristics of best quality paneer}

The paneer samples collected exhibited variations in the acceptance scores, especially overall acceptance scores. Based on the tabular analysis, the characteristics of all those paneer samples, which were scored higher than 7.5 (which was arbitrarily taken as a cut-off score for best acceptance of paneer), have been tabulated in Table 7 . Among all these parameters, notable ones are those of moisture content varying from $49.52-58.87 \%$ and fat $\%$ varying from $21-25.4 \%$. The low fat paneer resulted in lower acceptance scores. However, the values of parameters given in Table 7 are only indicative and suggestive and statistically derived ones because weak correlations observed in the study.

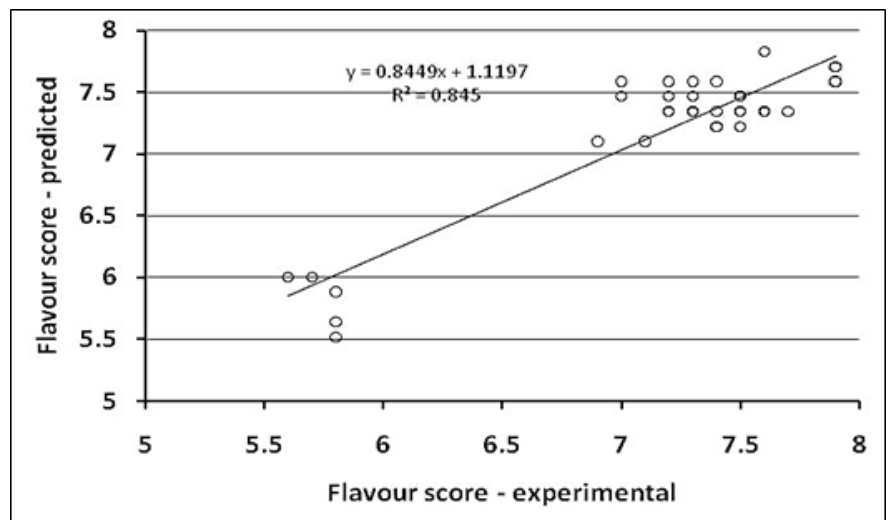

Note: predicted values computed from model: Flavour score = $1.782+1.2168$. Fat $\%\left(\mathrm{R}^{2} 0.85\right)$

Fig 3: Residual plot of experimental flavor scores and predicted flavor scores

\section{Conclusion}

Correlations were studied among sensory, physic-chemical, textural, and microbiological parameters of paneer samples. Most of these showed poor correlations, $r$ value being less than 0.70. However, some good correlations were noted like: body and texture score versus fat content $(r=0.879)$, flavor score versus body and texture score $(\mathrm{r}=0.931)$, overall acceptance score versus body and texture score $(\mathrm{r}=0.974)$, overall acceptance score versus flavor score $(r=0.947)$ and chewiness verses gumminess $(r=0.932)$. Regression analyses indicated a good fit for some univariate and multiple linear models. The univariate model was the best fit for BT score Vs. Fat\%; Flavour score Vs. BT score; Multiple linear models were best fit for Flavour score Vs. Moisture \%+Fat $\%+$ Protein $\%+$ Lactose $\%+$ Minerals $\%+$ Acidity $\%$; Overall acceptance score Vs. Color and appearance + Flavour +Body and texture score. This indicates that the above relationships do follow a mathematical pattern and can be predicted from each other satisfactorily. For example, we can predict BT acceptance based on fat content. We can predict flavor acceptance from chemical composition and acidity. We can predict flavor acceptance from BT, which means if BT is good, most probably flavor is also good. Not only can a judge score OA himself, but also it is possible to predict the OA score from CA, flavor, and BT scores.

Table 7: Characteristics of most accepted paneer samples

\begin{tabular}{|c|c|c|}
\hline $\begin{array}{c}\text { S. } \\
\text { No. }\end{array}$ & Parameter & $\begin{array}{c}\text { Overall acceptance score between } \\
\mathbf{7 . 5 - 7 . 8}\end{array}$ \\
\hline 1 & Colour parameters: a & $124.03-126.86$ \\
\hline 2 & b & $137.83-158.25$ \\
\hline 3 & pH & $5.1-6.29$ \\
\hline 4 & $\begin{array}{c}\text { Textural parameters: } \\
\text { Hardness, N }\end{array}$ & $21.01-58.08$ \\
\hline 5 & Adhesiveness, N.sec & $0.05-0.96$ \\
\hline 6 & Cohesiveness & $0.38-0.71$ \\
\hline 7 & Springiness & $0.31-0.98$ \\
\hline 8 & Gumminess, N & $11.29-35.76$ \\
\hline 9 & Chewiness, N & $9.04-24.05$ \\
\hline 10 & Chemical parameters: & $2.93-7.84$ \\
\hline 11 & Resilience & $49.52-58.87$ \\
\hline 12 & Moisture\% & $21-25.4$ \\
\hline 13 & Fat\% & $15.53-24.08$ \\
\hline 14 & Protein\% & $0.09-6.87$ \\
\hline 15 & Lactose\% & $1.46-1.96$ \\
\hline 16 & Ash\% & $0.31-0.90$ \\
\hline & Acidity\% LA & $10.5-43.5$ \\
\hline 17 & Microbiological & $7.5-24$ \\
\hline 18 & YMC, per g & \\
\hline
\end{tabular}

\section{Acknowledgment}

The authors thank the "Food Safety and Quality Assurance under Dairy Technology Division" National Dairy Research Institute, SRS Bangalore, ICRI-NDRI for the financial support. The authors declare that there is no conflict of interest.

\section{References}

1. Adhikari K, Heymann H, and Huff H E. Textural characteristics of low fat, full fat and smoked cheeses: sensory and instrumental approaches. Food Quality and Preference 2003; 14(2):211-218.

2. Agarwal A K. and Das H. A review on types of milk used for preparation, yield, chemical composition and quality attributes of paneer. Indian Journal Nutrition and Dibetics 2001; 38(4):64-72.

3. Akoglu H. User's guide to correlation coefficients. Turkish journal of emergency medicine 2010; 18(2):91-93.

4. AOAC. Official methods of analysis of the Association of Official Analytical Chemists. $15^{\text {th }}$ edition, Washington, USA, 1990, 104-114.

5. AOAC. Official methods of analysis of AOAC international. $18^{\text {th }}$ edition Washington DC, USA, 2005, 201-210. 
6. Awad S, Hassan AN, Halaweish F. Application of exopolysaccharide producing cultures in reduced fat cheddar cheese: composition and proteolysis. Journal Dairy Science 2005; 88(4):4195-4203.

7. Baig MD, Malik A, Kumar MD, Bumbadiya M, Raja Kumar SN, Beena AK. Optimization of calcium gluconate and Bacopa monniera extract levels in calcium enriched herbal ice cream by response surface methodology. Journal of food science and technology. 2019; 56(7):3320-3328.

8. BIS IS: 1224 Determination of fat by Gerber method. (Part 1). Milk (First Revision). Manak Bhawan, New Delhi, 1977, 14-20.

9. BIS Handbook of Food Analysis. SP: 18 (Part XI-1981). Methods of sampling and microbiological examination, Dairy Products, Manak Bhavan, New delhi, 1981, 29-35.

10. BIS IS: 10484 Hand book of food analysis. FAD 19: Dairy Products and Equipment, Manak Bhawan, New Delhi, 1983, 33-38.

11. Borrin TR, Georges EL, Brito-Oliveira TC, Moraes IC, Pinho SC. Technological and sensory evaluation of pineapple ice creams incorporating curcumin-loaded nanoemulsions obtained by the emulsion inversion point method. International journal of dairy technology. 2018; 71:491-500.

12. Bourne MC. Food texture and viscosity: concept and measurement, Academic Press London, 2002, 293-295.

13. Casiraghi E, Lucisano M, Pompei C. Correlation among instrumental texture, sensory texture and chemical composition of five Italian cheeses. Italian Journal Food Science. 1989; 11(3):53-63.

14. Chandan RC. Manufacturing of paneer in India. Dairy India, Sixth Ed, Dairy India Yearbook, Priyadarshini Vihar, New Delhi, 2007, 411-412.

15. Chitranayak Manjunatha M, Rekha MR, Magdaline FEE, Rao KJ, Varalakshmi S, Deshpande S. Physico-chemical characterization of paneer assessed by varying pressuretime combination. Indian Journal of Dairy Science. 2017; 70(4):280-293.

16. Das D, Ghatak PK. A study on the quality of paneer marketed at greater Calcutta. Journal Dairying Foods Home Science 1999; 18(2):49-51.

17. Desale RJ, Dhole PT, Deshmukh AR, Nimase RG. Studies on quality evaluation of market paneer. Asian Journal of Animal Science 2009; 4(1):73-74.

18. Dhankhar. Qualitative Comparative Assay of Different Paneer Samples. International Journal of Engineering Science Invention 2014; 3(1):27-30.

19. Di Monaco R, Cavella S, Masi P. Predicting sensory cohesiveness, hardness and springiness of solid foods from instrumental measurements. Journal of Texture Studies 2008; 39(2):129-149.

20. Drake MA, Gerard PD, Truong VD and Daubert CR. Relationship between instrumental and sensory measurements of cheese texture. Journal of Texture Studies 1999; 30(5):451-476.

21. Dwarakanath H, Gurumoorthi P, Sutariya H, Jayaraj Rao $\mathrm{K}$, Pagote $\mathrm{CN}$. Effect of freezing on the textural attributes of paneer during storage. Indian Journal Dairy Science. 2013; 66(3):487-495.

22. Fernandez-Martin F. Influence of temperature and composition on some physical properties of milk and milk concentrates. II. Viscocity. Journal Dairy Research. 1972; 39(2):75-82.
23. Goyal RK, Singh PK, Goyal SK. Studies on quality evaluation of market paneer. International Journal Agricultureal Science 2007; 3(1):165-167.

24. Hough G, Califano AN, Bertola NC, Bevilacqua AE, Martinez E, Vega MJ, Zaritzky NE. Partial least squares correlations between sensory and instrumental measurements of flavor and texture for Reggianito grating cheese. Food Quality and Preference 1996; $7(2): 47-53$.

25. Janhøj T, Petersen C B, Frøst M B and Ipsen R. Sensory and rheological characterization of low-fat stirred yogurt. Journal of Texture Studies 2006; 37(1):276-299.

26. Khamrui K, Dutta S, Dave K. Effect of frying, freezing and rehydration on texture profile of paneer and relationships between its instrumental and sensory textural attributes. Milchwissenschaft-Milk Science International. 2004; 59(4):640-645.

27. Khan SU, Pal MA. Paneer production: A review. Journal of food science and technology. 2011; 48(2):645-660.

28. Kumar S, Rai DC, Niranjan K, Bhat ZF. Paneer-An Indian soft cheese variant: A review. Journal of food science and technology 2014; 51(2):821-831.

29. Masud T, Shehla S, Khurram M. Paneer (White cheese) from buffalo milk. Biotechnology \& Biotechnological Equipment. 2007; 21(5):451-452.

30. Meullenet JF, Lyon BG, Carpenter JA, Lyon CE. Relationship between sensory and instrumental texture profile attributes. Journal of sensory studies. 1998; 13(1):77-93.

31. Peryam DR, Pilgrim FJ. Hedonic scale method of measuring food preferences. Food technology. 1957; 44(2):501-510.

32. Skriver A, Holstborg J, Qvist KB. Relation between sensory texture analysis and rheological properties of stirred yogurt. Journal of Dairy Research. 1999; 66(4):609-618.

33. Vital ACP, Santos NW, Matumoto-Pintro PT, da Silva Scapim MR, Madrona GS. Ice cream supplemented with grape juice residue as a source of antioxidants. International journal of dairy technology. 2018; 71(1):183-189.

34. Vyawahare AS, Rao KJ. Application of computer vision systems in colour evaluation of kunda: a heat desiccated dairy product. International Journal of Dairy Science. 2012; 6(1):253-266.

35. Yamul DK, Galmarini MV, Lupano CE, Zamora MC. Whey protein concentrate gels with different sucrose content: instrumental texture measurements and sensory perception. International dairy journal. 2013; 28(2):2431.

36. Wangdare S, Rao KJ, Mishra D, Datir R. PhysicoChemical, Sensory, Textural, and Microbiological Quality of Paneer (Indian Cottage Cheese) Marketed in Bengaluru City. Indian Journal of Marketing. 2017; 47(3):7-17. 